Professor Adjunto da UFBA

Faculdade de Educação

Professor Titular da UCSAL

Escola Superior de Educação Física

\title{
Capoeira e Educação Física: um resgate histórico
}

Esse artigo se reporta à relação existente entre a Capoeira e a Educação Física, passando por um resgate histórico. Pretendemos dar uma visão geral de como começou a prática da Educação Física no Brasil e de que maneira foi introduzida nos estabelecimentos de ensino, bem como assinalar as influências que os métodos de ginástica de origem estrangeira tiveram sobre a Educação e a Cultura Brasileira e como a Capoeira se relaciona com a Educação Física, integrando-se como um método de Ginástica brasileiro.

This article reports the relationship between capoeira and physical education going through on historical background. We are going to give a general view of how the physical education practices had started in Brasil, and how it was translated to educational establishment. We also would like to emphasize the influence of the facing gymnastics methods in the Brazilian culture and education, and what is the relationship between capoeira and physical education being itegrate with the brazilian gymnastics methods. 
Não podemos fazer uma relação entre a Capoeira e a Educação Física, sem antes resgatar a história da Educação Física brasileira, para entendermos como esta foi implantada no País, quais as influências dos métodos estrangeiros e como a Capoeira passa a se inserir neste contexto.

Resgatar a história da Educação Física brasileira não é uma tarefa fácil de realizar, pois nos deparamos com barreiras que comprometem e atravancam a memória brasileira.

Não existem bastante publicações sobre o assunto e as fontes primárias nem sempre estão devidamente conservadas, guardadas, catalogadas e dispostas à consulta da comunidade, em especial, dos pesquisadores.

O que pretendemos é dar uma visão geral de como começou a prática da Educação Física no Brasil e de que maneira esta foi introduzida nos estabelecimentos de ensino, bem como assinalar as influências que os métodos de ginástica de origem estrangeira tiveram sobre a Educação e a Cultura Brasileira e como a Capoeira se relaciona com a Educação Física, passando a fazer parte da mesma.

Em princípio, o ato de movimentar-se nasce com o homem, portanto a Educação Física baseia-se nas atividades naturais do homem: correr, saltar e arremessar, conjugadas com o sentimento, a emoção, a socialização, a biologização, a criatividade e a liberdade.

Marinho (1984, 19), reportando-se aos estádios filosóficos das atividades físicas do homem Pré-Histórico, afirma:

...0 homem pré-histórico, em contacto com a natureza não poderia deixar de ter uma filosofia de vida inteiramente naturalista. Ele era um animal com atividade própria e que, em conseqüência, tinha de, valendose de suas faculdades naturais, sobreviver. O homem marchava, mas os outros animais também marchavam. O homem corria, mas os outros animais também corriam. O homem saltava, transportava, lutava, mas isto todos os animais também faziam. Mas havia uma faculdade que Ihe era própria, que lhe era específica $e$ a qual, sobretudo, se deve ter o homem conseguido sobreviver. Ele podia realizar um gesto que os outros animais não realizavam. A esse gesto, atávico, deve-se a sobrevivência do homem. O homem podia atirar objetos e, com essa faculdade, atingir seus inimigos ou as feras, antes de entrar em luta corpo a corpo.

Observando esses princípios da Educação Física e a filosofia da maneira de sobreviver do homem pré-histórico é que chegamos aos índios que habitavam o Brasil no século XVI, e daí afirmarmos que 
a Educação Física brasileira nasce também da circunstância de sobreviver dos nossos índios.

Eles viviam em contato direto com a natureza e necessitavam de sua força física, agilidade e destreza para a manutenção de sua própria existência. E a sua sobrevivência estava diretamente relacionada com a lei da seleção natural em ferrenhos combates com as feras e outros semelhantes.

Os historiadores Simão de Vasconcelos e Jean de Lery (apud Marinho \& Accioly, 1956, 155) afirmam textualmente que os nossos índios "por ordinário eram membrudos, corpulentos, bem dispostos, robustos e forçosos" e que causavam admiração aos europeus.

Convivendo com a natureza é de se imaginar que, para se alimentar, faziam uso da pesca e da caça, usando armas rudimentares como o tacape e o arco e flecha. Lery (apud Marinho \& Accioly, 1956, 157) enaltece o índio brasileiro falando da "coragem inaudita com que os índios do Brasil empreendiam os seus combates" e destaca a desenvoltura como utilizavam o arco, a flecha e o tacape.

$\mathrm{Na}$ verdade, naturalmente e inconscientemente, eles iam muito mais adiante no uso da prática da atividade física, praticando a corrida, a natação, a canoagem e até a equitação.

Quanto à corrida a pé, podemos supor que foi muito praticada, pois a usavam na atividade da caça e na guerra. Frei Vicente Salvador (apud Marinho \& Accio/y, 1956, 156), estudando o modo de guerrear dos gentios do Brasil, esclarece que eles levavam "...as suas espias adiante, que são mancebos mui ligeiros...".

A natação foi muito praticada, quer seja nos rios ou no mar. Os filhos dos índios, ainda recém-nascidos, eram colocados em contato com a água do mar ou dos rios, a fim de se adaptarem e se acostumarem rapidamente e para não perderem a forma natural de nadar. Vários historiadores são unânimes em conceber essas qualidades dos índios. Eles eram essencialmente fluviais, excelentes nadadores e canoeiros insignes.

$\mathrm{Na}$ equitação, destacavam-se os Guaicurus, oriundos do sul do Mato Grosso, e os historiadores Francisco Rodrigues Prado e Pedro Calmon (apud Marinho, s.d.,16) citam que os índios dessa tribo eram "peritos na arte eqüestre", que amavam o animal e o utilizavam nos combates com muita maestria.

Quanto à prática da canoagem, sabe-se que os índios faziam as canoas de uma casca de árvore, as quais arrancavam de cima 
para baixo. Uma vez na água, usavam duas formas de remar, em pé ou sentado, a depender do tipo de remo, cabo longo ou curto. Normalmente, saíam em grupos grandes de, aproximadamente, 40 a 50 pessoas.

Uma outra manifestação importante de atividade física eram as suas danças, quer sejam rituais de guerra ou religiosa, nas quais são notórias a exacerbação do ritmo, as cantigas e o movimento, que exigiam muito da condição física do índio. Muitas dessas danças rituais eram bastante longas, chegando mesmo a durar dois dias.

Em 1549, houve a chegada dos jesuítas e a instalação dos célebres colégios que, na sua programação, contavam sempre com a atividade física, mesmo porque a disciplina era bastante rígida e ia de encontro ao espírito irrequieto dos selvagens catecúmenos. Como as aulas aconteciam no turno da manhã e no turno da tarde, os jovens índios não dispunham de todo o tempo livre para expansão das suas brincadeiras, por esse motivo as atividades físicas faziam parte da sua educação.

Com a Independência do Brasil, passa a existir uma preocupação mais intensa sobre a educação brasileira e a educação física aparece com destaque em alguns momentos. O principal acontecimento no período do Brasil-Império, contudo, são os afamados pareceres de Rui Barbosa, ao qual nos reportaremos mais adiante.

É importante citar alguns episódios que marcaram um esforço muito grande no avanço da Educação Física, quer seja curricular ou não. Mas em todos esses fatos existe uma consciência do valor da Educação Física como um instrumento de educação e saúde.

Em 1828, foi editado o primeiro livro com o título Tratado de educação física - moral dos meninos, sendo seu autor Joaquim Jerônimo Serpa. Um outro trabalho aparece em 1845, é o de autoria do Dr. Manoel Pereira da Silva Ubatuba. É uma tese que tem como título Algumas Considerações sobre a Educação Física. E, em seguida, o Dr. Joaquim de Pedro Meio defende outra tese intitulada Generalidades acerca da Educação Física dos Meninos.

Dois relatórios chamam a atenção sobre o assunto: o primeiro de A. Gonçalves Dias, encarregado de fazer os relatórios das províncias do Norte, apresenta trecho bastante expressivo:

Vê-se pois que os professores alguma coisa, ainda que pouco, fazem, quanto ao desenvolvimento intelectual dos meninos: no físico absolutamente nada, nem mesmo os primeiros exercícios de ginástica, ou jogos, que fortifiquem o corpo; no do moral, quase nada; porque a 
Educação é para eles negócio de pouca importância. (apud

Marinho \& Accioly, 1956, 159).

O segundo relatório, datado de 1860, é apresentado pelo inspe tor geral da instrução pública do Município da Corte, do qual se destaca o seguinte trecho:

\begin{abstract}
Os exercícios ginásticos que desejo ver quanto antes introduzidos nas escolas promovendo a Educação Física da mocidade que as freqüenta, sendo das necessidades bem urgente do ensino público primário, ainda ficaram adiados por falta de espaço e de acomodações nos prédios atuais. (apudAccioly\& Marinho, 1956, 159)
\end{abstract}

Durante este período, nota-se realmente a precariedade das es colas e de suas instalações, especialmente as áreas próprias para a educação física, as quais perduram até os dias de hoje. Também verificamos que o sexo feminino não tinha acesso à prática da ginástica, em virtude do forte preconceito, quanto às potencial idades e habilidades da mulher.

No entanto, podemos destacar um marco na história da Educação Física brasileira que trouxe um novo alento para seu desenvolvimento que foi o parecer de Rui Barbosa, de 12 de setembro de 1882.

Leite (apud Marinho) que ressalta a contribuição de Rui Barbosa à Educação Física através da seguinte colocação:

Quem pretendesse, ainda nos dias que correm, justificar a necessidade da educação física para a formação integral do homem, por certo não conseguiria fazê-lo com tanta lógica, com tanta precisão de conceitos, nem com maior abundância de argumentos do que fez Rui Barbosa,no "Parecer e Projeto da Comissão de Instrução Pública': apresentado à Câmara dos Deputados em 12 de setembro de 1882. (1980,13).

Inezil Penna Marinho, em 1980, homenageia Rui Barbosa com uma publicação intitulada o Rui Barbosa, paladino da educação física no Brasil, na qual revela aspectos particulares, destacando que Rui, mesmo pouco afeiçoado aos exercícios físicos, reconhece a sua importância na educação integral do homem e coloca toda sua sensibilidade, inteligência, talento e cultura na defesa da Educação Física, ao redigir os pareceres sobre as Reformas do Ensino Secundário e Superior e do Ensino Primário e Várias Instituições Complementares em 1882.

A partir de Rui Barbosa é que encontramos as idéias fundamentais a respeito da Educação Física formal, que podem ser assim consubstanciadas: 
a) obrigatoriedade da Educação Física no jardim da infância, escola primária e escola secundária, inclusive os cursos industriais, de comércio e agricultura, como matéria de estudo, em horas distintas das do recreio e depois das aulas;

b) instituição dos exercícios militares para alunos do sexo masculino, a partir da escola primária;

c) distinção entre os exercícios físicos para os alunos (ginástica sueca) e para as alunas (calistenia), de modo que a mulher praticasse atividades compatíveis com as características de seu sexo, a harmonia das formas feminis e as exigências da maternidade futura;

d) prática de exercícios físicos pelo menos quatro vezes por semana, durante 30 minutos, devendo ser professada a ginástica exclusivamente higiênica e pedagógica, sem caráter acrobático;

e) valorização do professor de Educação Física, dando-Ihe paridade, em direitos e vencimentos, categoria e autoridade, aos demais professores;

f) preferência, nas nomeações e acessos, aos professores que tivessem habilitação no ensino da ginástica escolar, quando em igualdade de condições com os demais;

g) instituição de uma seção especial de Educação Física em cada escola normal;

h) contratação de professores de Educação Física, de com petência reconhecida, na Suécia, Saxônia e Suíça;

i) dispensa dos exercícios físicos somente para os alunos que, por inspeção médica, fossem declarados incapazes;

a) horário integral e dedicação exclusiva para os lentes do Liceu Imperial Pedro 11, Liceus Gerais e Liceus Provinciais, que conferirem bacharelado em ciências e letras.

b) instituição de um curso de emergência em cada escola normal, para habilitar os professores atuais de primeiras letras ao

ensino da ginástica, curso esse gratuito e com funcionamento à noite. (Marinho, s.d., 28).

Os itens apresentados acima denotam a preocupação em ordenar a Educação Física brasileira, valorizando-a como uma ferramenta importantíssima na formação dos cidadãos brasileiros da época Influência dos métodos de ginástica. 
Desde a colonização do Brasil e no Império, com o esforço de implantar uma Educação Física nas Escolas, haja vista os importantes pareceres de Rui Barbosa sobre as reformas na educação brasileira, é que podemos trazer à tona os métodos de ginástica que aportaram no País e suas influências.

A ginástica de origem alemã

A ginástica alemã chega ao Brasil na segunda metade do século XIX, trazida pelos imigrantes alemães que se estabeleceram no sul do País, soldados e oficiais prussianos que integravam a Guarda Imperial.

O método alemão, de filosofia ri.\&dda e Que Incen1iyaya $D$ p.a1r.iD . pi'JIMim:IJIJEIJ'M::: :JJD semr 1Tilü1aT. me

gando ao auge em 1860, quando o oficial, de nacionalidade alemã, Pedro Guilhermino Meyer, é nomeado contramestre de ginástica da Escola Militar. Esse fato veio consagrar o referido método no Brasil, ao ponto de ser oficializado pela Escola Militar em 1912. Outro acontecimento relevante, e que gerou controvérsia, foi a publicação, por ordem do Ministro do Império, do Novo guia para o ensino da ginástica nas escolas públicas da Prússia. Esse guia suscitou uma grande reação para que o método alemão não fosse implantado nas escolas e a mais significativa delas encontra-se no Parecer de Rui Barbosa sobre a Reforma do Ensino Primário e Várias Instituições Complementares da Instrução Pública, que se contrapõe ao método alemão e propõe sua substituição pelo método sueco.

Sendo a Alemanha derrotada na Primeira Guerra Mundial (1914 - 1918), e coincidindo com a chegada da Missão Militar Francesa ao Brasil, o método começou a perder credibilidade, dando espaço para o método francês.

Método francês de ginástica

O método francês tem sua origem na Escola de Joinville LePont, fundada em 15 de julho de 1852, com Dom Francisco Amoros y Ondeano que, segundo alguns autores, se inspirou em Guths-Muths, sofrendo também forte influência de Rabelais. Desse modo, a linha da doutrina francesa é assinalada da seguinte forma: Rabelais - Amoros Demeny - Herbert - Joinville - Herbert. (apud Marinho, s.d., 48) 
Vale ressaltar que o método alemão foi oficialmente substituído no Brasil em 27 de abril de 1921, pelo Decreto nQ 14.784, assinado pelo então Presidente da República, Epitácio Pessoa, e pelo Ministro da Guerra, João Pandiá Calógeras. Com a assinatura desse ato, o Método Francês passa a fazer parte de todas as armas. E, em abril de 1931, com as reformas do ensino secundário, é estabelecida a obrigatoriedade dos exercícios e educação física para todas as classes. A partir daí, são editados os programas de Educação Física fundamentados no método francês.

Em 30 de junho de 1927, o Dr. Jorge de Moraes, então deputado pelo Estado do Amazonas, apresenta um projeto para a criação de duas escolas de Educação Física, sendo uma civil e outra militar.

Mais à frente, em 1929, o General Nestor Pessoa apresenta um anteprojeto para a prática da Educação Física, destacando-se os seguintes artigos:

a) Art. 19 - A Educação Física deve ser praticada por todos os residentes no Brasil. Ela é obrigatória em todos os estabelecimentos de ensino federais, municipais e particulares, a partir da idade de seis anos, para ambos os sexos.

b) Art. 419 - Enquanto não for criado o "Método Nacional de Educação Física", fica adotado em todo Território Brasileiro o denominado Método Francês sob o título de Regulamento Geral de Educação Física. (Marinho, s.d., 56-57)

Portanto, o citado método de ginástica tem uma influência marcante na Educação Física do País e seus programas vigoram até o ano de 1944.

\section{o método da calistenia}

O termo calistenia originou-se do grego: kallos = belo e sthenos = força e foi empregada pela primeira vez, em 1785, na Escola de Salzmam, quando Carl André organizou planos de ginástica para serem ministrados a seus alunos, em recintos fechados, nos dias chuvosos. Podemos situar a calistenia no contexto da Educação Física como um método que se baseia nos exercícios analíticos de efeitos localizados, praticados com implementos como halteres, bastões, bolas, maça etc. ou a mãos livres.

A calistenia tem como finalidade combater os efeitos nocivos do modernismo das grandes cidades, aliado ao avanço da tecnologia e 
aos maus hábitos adquiridos. Atua especialmente estimulando os grandes grupamentos musculares, agindo na prevenção dos vícios posturais, e desenvolve as grandes funções, especialmente o aparelho cardiovascular e demais órgãos.

AAssociação Cristã de Moços-ACM, instituição norte-americana, foi a grande responsável pela divulgação desse sistema, tendo àfrente William Wood e Robert Jefries, que introduziram, em seus programas de Educação Física, a "Nova Ginástica de Lewis", que nada mais era que o resumo dos exercícios livres e da calistenia, executados com halteres, maças, bastões, bolas e passos de dança. AACM foi a grande responsável pela introdução da calistenia na América do Sul e, segundo Paiva $(1980,44)$, contou com dois grandes apologistasAlfred Wood, idealizador da curva de esforço que foi batizada com o seu nome, e William Skarstron, que foi o responsável pela outra curva de esforço que leva o seu nome.

Sabe-se que no Brasil a primeira referência a favor da adoção da calistenia aparece nos pareceres de Rui Barbosa que, inspirado no trabalho de Clias, publicado em 1829, destaca a importância da calistenia para o sexo feminino, justificando que as mulheres deviam praticar atividades de ginástica compatíveis com as características do sexo, harmonia das formas e preocupação das exigências da maternidade futura.

E a calistenia se consuma no País por meio da instalação da ACM na Cidade do Rio de Janeiro, em 1893, nos moldes da Associação Americana, a qual passa a ter um papel fundamental no desenvolvimento das atividades físicas e desportivas, sobressaindo o voleibol e o basquetebol.

Método sueco de ginástica

o criador do método sueco é Per Henrik Ung, que nasceu na cidade Lyunger, em 15 de novembro de 1776, e teve uma infância e adolescência conturbada com a perda precoce dos pais. Estudou nas Universidades de Lund e Upsala e sua formação teve uma forte influência de autores dinamarqueses e alemães. Era poeta lírico, tendo ingressado na Academia Sueca em 1835, e obtendo em 1837 um dos maiores prêmios literários do Rei Charles-Jean.

A primeira manifestação a favor da implantação da ginástica sueca, em nosso País, aconteceu quando Rui Barbosa emitiu seus célebres pareceres, por ocasião das Reformas do Ensino Secundário e Superior e do Ensino Primário e Várias Instituições Complementares. Nestes, fica evidenciada a distinção de exercícios físicos para os sexos masculino e feminino, sendo a ginástica sueca indicada apenas para os alunos. 
Durante o período de 1888 a 1920, várias publicações foram produzidas as quais correlacionavam a prática da Educação Física nas Escolas Públicas, Colégios, Liceus e Escolas Normais e Municipais com a aplicação do citado método.

O primeiro livro é de Pedro Manuel Borges e tem o título Manual Teórico-Prático de Ginástica Escolar (elementar e superior), sendo publicado em 1888 com uma influência marcante nos estabelecimentos de ensino, induzindo paulatinamente que o método alemão ficasse restrito aos estabelecimentos militares.

Outra publicação de relevante repercussão é o livro de Arthur Higgins, intitulado Compêndio de Ginástica e Jogos Escolares, publicado em 1896, e sendo adotado pela Escola Normal e Ginásio Nacional, na Cidade do Rio de Janeiro, contribuindo assim para a disseminação da ginástica sueca entre as escolas civis brasileiras.

Outros fatos importantes da época marcaram decisivamente a influência do método sueco na educação brasileira. Foram eles:

a) em maio de 1901, o Dr. Domingos Jaguaribe funda, em São Paulo, o Instituto Jaquaribe. Esta instituição destinavase principalmente à ginástica corretiva, adotando o método sueco, e dessa maneira conquistando a sociedade paulistana;

b) em 21 de setembro de 1905, o Dr. Jorge de Moraes, deputado pelo Estado do Amazonas, faz um longo discurso na Câmara dos Deputados a fim de justificar seu projeto, que criava duas Escolas de Educação Física, sendo uma civil e outra militar. Nesta oportunidade, a exemplo de Rui Barbosa, teceu criticas ao método alemão e fez apologia ao método sueco;

c) em 1911, Arthur Higgins, um divulgador do método sueco nas escolas primárias e secundárias do Rio de Janeiro, publica uma segunda edição do seu Compêndio de ginástica escolar, refundido, ilustrado e com 222 páginas. Esse livro foi aprovado pela Diretoria Geral de Instrução Municipal e, posteriormente, adotado oficialmente no Distrito Federal;

d) em 1915, Fernando de Azevedo, professor substituto de latim do Ginásio Mineiro, de Belo Horizonte, publica duas meritórias obras - A poesia do corpo ou a ginástica escolar, uma tese que escreveu para o concurso da cadeira de Ginástica e Educação Física, na qual recomenda a ginástica sueca para as escolas brasileiras e o livro, editado em 1920, intitulado Da Educação Física, que questiona o presente e o futuro da Educação Física. 
$p \sim \sim \sim 0 \sim \sim \mathrm{d} 6 \mathrm{krriW}$ 'cTmente o espaço escolar e o método alemão fica restrito cada vez mais aos estabelecimentos militares.

\section{Capoeira, o método brasileiro de ginástica}

Há muito os professores de Educação Física vêm lutando para a criação de um método brasileiro de ginástica. No século passado, os métodos de ginástica foram importados e introduzidos no Brasil através das forças armadas, principalmente, no Exército, para, depois, serem disseminados nas escolas e liceus.

Os principais métodos que adentraram e influenciaram a Educação Física no País, além dos já citados, Método Sueco, Método Alemão, Método Francês, Método da Calistenia, foram: o Método Dinamarquês, o Método Natural Austríaco e o Método da Desportiva Gene ralizada.

Não havendo pessoas qualificadas no Brasil, foi necessário importar professores e instrutores, que vieram a convite do Governo Brasileiro, com o objetivo de difundir a ginástica e suprir a enorme carência na área. Posteriormente, passaram a ministrar cursos de emergência, os quais credenciavam instrutores, na sua maioria militares, para lecionarem nas instituições de ensino.

Tomando vulto a idéia de a Educação Física brasileira adotar o próprio método de ginástica, é que a primeira iniciativa da Capoeira como ginástica aparece em 1907 com o opúsculo intituJado O guia do capoeira ou gymnastica brazileira, de OOC. A Capoeira era, porém, uma forma de luta, jogo ou defesa pessoal altamente reprimida, por ser praticada por escravos, fugftivos, ma\{andros e desordeiros.

Soares $(1994,27)$ diz que a Capoeira não era usada apenas contra policiais, soldados ou senhores violentos. Ela servia para acertar diferenças e marcar hierarquias dentro da própria comunidade escrava.

Araújo conceitua como capoeira (s):

...indivíduo (s) ou grupos de indivíduos que promoviam ações criminosas que atentavam contra a integridade física e patrimonial dos cidadãos, nos espaços circunscritos dos centros urbanos ou área de entomo. $(1997,65)$

Em 1928, aparece uma nova iniciativa para transformar a Capo eira em método de ginástica, através de Annibal Burlamaqui, que publica um trabalho com o título de Gymnastica Nacional (capoeiragem) Methodisada e Regrada. 
Burlamaqui, cognominado Zuma, procura sistematizar a Capoeira como um esporte nacional, e Mario Santos deixa claro, no prefácio, essa preocupação, quando expressa: "Actualmente até o polo e golf já são disputados em nossa terra. No entanto é de lamentar que até hoje nada se tenha feito em prol do sport nacional" . Ainda faz comparações a respeito de proposições para arte, música e política brasileira, enquanto que, para a invenção de um esporte nacional, infelizmente pouco movimento se fazia, acrescentando que esta iniciativa de Burlamaqui é um brado de brasilidade.

Nesse compêndio, o autor, ao se referir sobre a Capoeira como ginástica brasileira, sempre traz um enfoque da sistematização do esporte luta, para o qual propõe basicamente as regras (espaço de luta, apresentação dos lutadores, empate e desempate, juiz e indumentária) e, também, relaciona os golpes com as respectivas descrições e ilustrações. Indica, além do mais, exercícios e formas de treinamento.

$\mathrm{Na}$ fundamentação do seu trabalho, retrata a historicidade, destacando a capoeiragem como o instrumento de resistência, valorizando os seus praticantes pela sua habilidade motora incrivelmente desenvolvida que, aliada ao sangue frio e à astucia, fazia com que os escravos capoeiras fossem superiores nos combates corpo a corpo.

Mestre Bimba, o criador da Capoeira Regional, contribui para o assunto de uma maneira toda peculiar, quando em sua Academia de Capoeira Centro de Cultura Física Regional - CCFR, muitas vezes, disse ser a Capoeira, por si só, uma excelente forma de ginástica. Inclusive, em 1937, registrou o CCFR na Secretaria de Educação Saúde e Assistência Pública da Estado da Bahia.

Angelo Decanio Filho (Decanio), ex-aluno de Mestre Bimba, uns dos mais antigos e participativos, ainda em atividade, relata em seu livro A herança de MESTRE BIMBA (1996), no tópico intitulado "como surgiu a regional", que:

...Sr. Manoel dos Reis Machado...

...recebeu do Ministério da Educação...

...0 indispensável "diproma"...

... de Instrutor de Educação Física...

...devidamente assinado...

...pelo Or. Gustavo Capanema!

(Oecanio, 1996, 161) 
Esta citação denota a peculiaridade de aproximação entre a Capoeira e a Educação Física, pois o Ministério da Educação reconhecer o valor da Capoeira Regional e a capacidade de Mestre Bimba em transmitir, através de uma prática pedagógica, movimentos capoeirísticos entendidos como elementos ginásticos.

Mestre Bimba acreditava fielmente na sua Capoeira Regional e não mediu esforços para divulgá-la: subiu ao ringue, desfilou em cortejo cívico, fez apresentações para políticos, ministrou aulas no CPOR, excursionou, fez shows em clubes, ginásios, teatros e participou de simpósios.

Outro fator preponderante na caminhada da Capoeira até atingir o seio escolar, universitário e da Educação Física foi a oficialização da Capoeira pela Confederação Brasileira de Pugilismo em 26 de dezembro de 1972, a qual foi homologada pelo Conselho Nacional do Desporto (CND) em 26 de dezembro de 1973. Este foi o passo de fundamental importância para aproximar e estreitar a relação com a Educação Física, principalmente, levando-se em conta a apropriação do esporte como conteúdo indispensável na formação dos educandos.

Mestre Carlos Senna, ex-aluno de Mestre Bimba, um defensor ferrenho da Capoeira esporte e fundador da SENAVOX, em 1980, publicou um inusitado trabalho denominado Capoeira: arte marcial brasileira. Esta publicação mostra a preocupação do autor com os exames, corpo docente, regulamento de competição e súmulas. Ele fundamenta, também, seu projeto nos valores educacionais e reconhece ser a Capoeira uma "...incomparável forma de Educação Física...," assim descrita:

A CAPOEIRA, além das suas inúmeras vantagens, tais como ser linda aos olhos para quem aprecia, diversão, "relax" para quem pratica, ajuda a desenvolver o poder da vontade, cultiva a cortesia e patrocina a moderação da linguagem, coopera com a formação do caráter, dando àquele que a pratica uma mar cante sinceridade, induzindo a uma moral na qual procura sempre não atingir a dignidade do seu semelhante. Na intimidade, cultivam os que a praticam uma estima recíproca, substituindo por uma camaradagem fácil. Geralmente os capoeiristas, no seu olhar, demonstram beleza que trazem no coração e, também, a confiança em si mesmos.

É uma incomparável forma de educação física pelos movimentos acrobáticos que a mesma exige, quando numa "volta". É também um extraordinário método de defesa pessoal, pois, num combate corpo a corpo, contra elementos armados ou mesmo contra bandos, sua su 
perioridade e validade já foram comprovadas no presente e no passado. $(1980,8)$

Destacamos ainda o projeto do Professor Inezil Penna Marinho, em 1982, nomeando-a de Ginástica Brasileira. Este projeto toma corpo e motivação pela preocupação do incansável professor em criar um método de ginástica genuinamente nacional, valorizando as raízes histórico-sócio-culturais próprias do povo brasileiro.

Anteriormente, o próprio Inezil, quando Chefe da Seção Técnico-Pedagógica da Divisão de Educação Física do Ministério da Educação e Saúde, publicou Condições a que deverá satisfazer um Método Nacional de Educação Física (1946), trabalho este premiado pelo D.E.F., mas que não surtiu o efeito desejado pois os métodos estrangeiros estavam no momento muito arraigados no País.

A ginástica brasileira ressurge a 4 de dezembro de 1980, quando o Professor Inezil participou da "V Roda de Capoeira", patrocinada pela Secretaria de Educação e Cultura, Fundação Cultural e Clube de Capoeira Beribazu, em Brasília. Neste evento, participaram integrantes de grupos de Capoeira dos Estados da Bahia, Maranhão, Pernambuco, Alagoas, Rio de Janeiro, Paraíba, Minas Gerais, São Paulo e os anfitriões do Distrito Federal.

O método da ginástica brasileira tem uma visão globalizada e contempla os aspectos bio-psico-sócio-histórico-filosóficos, ressaltando, ainda, a adequação das faixas etárias e valorizando a cultura, o folclore e as atividades após a profissionalização e na terceira idade. Dessa forma, foi dividido em seções citadas a seguir:

Seção Cultural, Seção Técnico-Científica, Seção Pré-Escolar, Seção Escolar do 12 grau, Seção Escolar do 22 grau, Seção Universitária, Seção Pós-Universitária, Seção de Conservação, Seção Desportiva - A Capoeira, Seção Folclórica - A roda de Capoeira, Seção Marcial Capoeira Arte Marcial, Seção de Exercícios-Coletânea.

Inezi! divulgou seu projeto em todo o território brasileiro através de seminários, cursos, debates, painéis etc.

Contemporaneamente, a vinculação da Capoeira à Educação Física está estabelecida através da apropriação dos conteúdos do esporte nos programas da Educação Física escolar, em todos os níveis, inclusive nas universidades.

Esse vínculo torna-se cada vez mais forte, à medida que se reconhece o valor da Capoeira como esporte que presta uma contribuição toda peculiar para a formação integral dos jovens. Um esporte que 
é popular e possui um vigoroso substrato cultural que suscita nos educandos a cobiça pela investigação, o desejo de conhecer algo mais que simplesmente os golpes, contragolpes e esquivas da Capoeira, saber o porquê de jogar Capoeira e entender a sua historicidade, sua origem, seus percalços, resistência, evolução e modernidade.

Na última década, muitas têm sido as contribuições de Mestres de Capoeira que atuam especialmente nos cursos de Educação Física. Para Santos,

Alguns educadores estão descobrindo o valor dos movimentos da capoeira como exercícios físicos e válvula de escape de corpo e mente estressada, conscientizando pessoas da sua importância para a saúde física e mental de qualquer indivíduo que a pratica. $(1990,28)$

Ainda Santos $(1990,29)$, reportando-se ao assunto, diz que a Capoeira como a Educação Física é uma disciplina necessária dentro do sistema educacional e considera que ela tem uma história importantíssima de resistência que deve ser transmitida aos alunos, concomitantemente com os movimentos, a musicalidade, o canto e . até mesmo em diálogos democráticos participativos entre professor e aluno.

Temos afirmado, baseado em experiências pessoais, que o ensino da Capoeira deverá ser generalizado, não devendo contemplar somente o aspecto técnico de luta, defesa pessoal ou esporte; o ensino dos golpes e seqüências deverão ser acompanhados da transmissão de todos os elementos que envolvem a cultura, a história, a origem e a evolução, ao tempo em que se estimulará a pesquisa, o debate e a discussão em seminários, para que o educando tenha uma participação efetiva no contexto da Capoeira como um todo. A idéia de unidade nasce da participação do aluno no jogo, cântico, toques e ação teórica.

Outra contribuição relevante é a de Falcão $(1996,46)$ que realizou um abrangente estudo fundamentado em autores brasileiros como Guiraldelli Júnior, Betti, Beltrami, Medina e Bracht sobre as concepções da Educação Física no Brasil e sua relação com a Capoeira. O seu enfoque principal está norteado para uma Capoeira escolar, salvaguardando os interesses básicos para a utilização da capoeira como ferramenta educativa.

Porém, outros autores fazem essa relação Capoeira como Educação Física, observando principalmente as questões mais técnicas que possam consubstanciar o ensino-aprendizagem da Capoeira, norteada para o aspecto da performance. Nesta questão, é bastante 
comum o interesse dos estudos objetivando o rendimento atlético, então, torna-se imprescindível a preocupação com a preparação física e técnica.

Defendemos a idéia de que o ensino da Capoeira deve-se pautar em paradigmas da Educação Física e do Esporte, reconhecidos pela comunidade científica mundial. Esses paradigmas contribuirão no suporte teórico científico que servirá de lastro para garantir a segurança, facilitar o ensino e oportunizar a melhora do rendimento de maneira eficaz.

Concordando com essa idéia, Silva $(1989,18)$ afirma que no "...jogo da Capoeira são evidenciadas as qualidades físicas, tais como agilidade, destreza, coordenação, flexibilidade etc". Siega $(1998,9)$, reportando-se aos "Cuidados e contra-indicações", apresenta algumas considerações a respeito de métodos para o desenvolvimento das qualidades físicas: força, resistência, flexibilidade, velocidade, agilidade e equilíbrio. Neste estudo, chama atenção que a prática da Capoeira é excelente para propagar as qualidades físicas através dos movimentos capoeirísticos.

Zulu (1995,20), reportando-se à Capoeira Arte e Luta, a II conceitua da seguinte forma: "Capoeira é arte-luta brasileira formada pela conjugação do gesto-musicultura com as qualidades físicas, expressas pela movimentação constante...". Mergulhão, Romualdo e Prouvot (apud Silva 1995, 135), fazendo uma comparação e análise da ginástica artística e a capoeira, encontram elementos integrativos de cooperação mútua, dizendo que "...ginástica olímpica é um esporte que, por suas características, pode apresentar enormes benefícios para a capoeira...". E, mais adiante afirmam que "...no caso específico da capoeira, a ginástica auxilia sobremaneira nos equilíbrios, nos movimentos acrobáticos e no domínio das posições do corpo no espaço". Santana $(1989,21)$ entende que a ginástica é importante para o condicionamento físico-muscular, porém chama atenção que "...a capoeira em si já é uma boa ginástica".

A rigor, este parece ser o entendimento dos mestres de capoeira e professores de Educação Física que atuam na docência da capoeira, quer seja no ensino formal ou informal: a capoeira se presta enormemente para o desenvolvimento do condicionamento físico (orgânico e neuro-muscular), além de contribuir decisivamente com os aspectos cognitivo, afetivo e motor, estimulando a coragem, a autoconfiança, a auto-estima, a cooperação e a formação do caráter e da personalidade. 
Portanto, todos os indícios mostram que a relação da Capoeira com a Educação Física é de reciprocidade, e tanto os movimentos ginásticos naturais e analíticos, como os princípios e métodos de treinamento, são ferramentas que dão suporte técnico-científico ao ensino da capoeira. A reciproca, contudo, é verdadeira, principalmente quando se trata do ensino-aprendizado da capoeira, em que ela, por si mesma, é capaz atender às necessidades atléticas dos capoeiristas, desenvolvendo sobremaneira as capacidades aeróbica, anaeróbica, qualidades físicas e volutivas.

Pelos motivos expostos acima, podemos considerar a capoeira como o método de ginástica genuinamente brasileiro, pois atende às necessidades dos alunos, motivando-os a praticar uma ginástica que desperta um interesse peculiar, justamente por ser oriunda de uma manifestação popular, rica de movimentos, ritmo e música, com substrato cultural e bastante difundida na sociedade.

\section{REFERÊNciAS BibLioGRÁFicAs}

ALMEIDA, Raimundo Cesar Alves. A saga do Mestre Bimba. Salvador: 1994.

. Bimba Perfil do Mestre. Salvador: CEDUFBA, 1982,

ARAÚJO, Paulo Coelho de. Abordagem sócio-antropológicas da luta/jogo da capoeira. Porto: PUBLISMAI, 1997.

AREIAS, Almir das. O que é capoeira. São Paulo: Brasiliense, 1983.

AZEVÊDO, Evilásio R. Capoeira e aptidão física. Salvador: Policia Militar da Bahia, 1973.

BURLAMAQUI, Anibal. Gymnastica Nacional (capoeiragem) methodisada e regrada.

Rio de Janeiro: 1928.

CAMPOS, Helio. Capoeira na escola. Salvador. Presscolor, 1990.

. Capoeira, o método de ginástica brasileiro. Negaça. Salvador, 1992. Ano

I. (1): 46-49.

. A seqüência de Mestre Bimba, um jogo de ensino-aprendizagem. Revis ta da FACED/UFBA. Salvador, 1999, (2) 75-90.

. Capoeira um esporte brasileiro. Sprint magazine. Rio de Janeiro: 1997

:93) 19-22

. Capoeira na escola. Sprint magazine. Rio de Janeio: 1996 (86) 28-31.

. Capoeira e as qualidades físicas. In: TAVARES, Luiz Carlos (Org.), Cader $10 S$ de Capoeira. Aracaju: Universidade Federal de Sergipe, 1994 ;ASCUDO, Luiz da Câmara. Folclore do Brasil. pesquisas e notas. Brasil/Portugal: :undo de Cultura, 1967. 
FALCÃO, José Luiz Cirqueira. A escolarização da capoeira. Brasília: Editora Royal Court, 1996.

. Capoeira e/na educação física, Sprint magazine, Rio de Janeiro: 1995. Ano

XIV - (79):10-14.

FILHO, Angelo A. Decanio. A herança de Mestre Bimba. Salvador: 1996

GOÉS, Odilon Jorge Daltro. Os efeitos do treinamento de musculação na resistência

muscular localizada, para os estudantes de 1 fi e ${ }_{2 t 1}$ graus, na faixa etária de 16 a 18 anos

no Colégio Cameiro Ribeiro Filho. Monografia do Curso de Especialização em Treinamento

Desportivo. Rio de Janeiro: Universidade Gama Filho, 1985.

LUSSAC, Ricardo Martins Porto. Estudo da metodologia do ensino da capoeira. Sprint

magazine, Rio de Janeiro: 1996. Ano XV. (84):36-38.

MARINHO, Inezi! Penna. \& ACCIOL Y, Aluizio Ramos. História e organização da educação física e dos desportos. Rio de Janeiro: 1956.

MARINHO, Inezil Penna. A ginástica brasileira. Brasília: Edição do Autor, 1982. . Introdução ao estudo da filosofia da educação física e dos desportos.

Brasília: Horizonte editora Ltda., 1984.

. Sistemas e métodos de educação física. São Paulo: s.d.

. Rui Barbosa paladino da educação física no Brasil. Brasília: Horizonte

editora Ltda., 1980.

. História da educação física na Brasil. São Paulo: CIA Brasil Editora.

. Introdução ao estudo do folclore brasileiro. Brasília: Horizonte Editora

Ltda., 1980.

PAIVA, Pedro Alvares. Educação física principais sistemas e métodos. Minas Gerais: U.F. de Viçosa, 1980.

SANTANA, Mestre. Iniciação à capoeira. São Paulo: Editora Graund Ltda.,1989. SANTOS, Luis Silva. Educação - educação física - capoeira. Maringá: Fundação Universidade Estadual de Maringá, 1990.

SENNA, Carlos. Capoeira Percurso. Salvador: Edição do Autor, 1990. p.13.43

. Capoeira: arte marcial brasileira, Cadernos de cultura, N.Q 03, Salvador:

Prefeitura Municipal do Salvador, 1980.

SIEGA, Carson. Cuidados e contra-indicações. Jornal Muzenza. Curitiba: 1998. Ano

4 (33):9-11.

SILVA, Gladson de Oliveira. Capoeira do engenho à universidade. São Paulo: CEPEUSP 1995.

. Capoeira. São Paulo: CPUSP,1989

SOARES, Carlos Eugênio Líbano. A Negregada instituição. Rio de Janeiro: Secretaria Municipal de Cultura, 1994.

ZULU, Mestre. Idiopráxis de capoeira. Brasília: Fundação Educacional do Distrito Federal FEDF, 1995. 